\title{
A Study on the Strategies of Japanese Literature Teaching Assisted by the Network Optimization in the Information Age
}

\author{
Zhang Li
}

\author{
School of Foreign Languages, Xi'an University,710065
}

Keywords: Information age; Network optimization; Japanese literature; Teaching strategies

\begin{abstract}
Nowadays, the information technology develops rapidly, and the network is used by people more and more frequently. As the previous teaching model and method are too single, a variety of explorations on the teaching model have been done. And now, due to the rapid development of information technology, there are diverse methods for teaching through the network, and at the same time, the network-based teaching has also been popularized. Using the network to assist the Japanese literature teaching will break the settled teaching model, bringing new vitality to this subject, and the problems existing in the previous teaching model will be solved.
\end{abstract}

\section{Introduction}

In the context of information age nowadays, due to the rapid development of network technology, all walks of life can be combined with the network for innovation and transformation. The network wins people's favor because of its convenience and high efficiency, making the network-based teaching become more and more popular. Network optimization occupies a very important position in the network; if the network remains the initial structural pattern without corresponding optimization, the network would not be used in a variety of areas nowadays, and its performance would not be such superior now. Therefore, the network optimization leads the network towards a better and better development[1]. This paper mainly studies and briefly analyzes the advantages of network optimization in teaching strategies of Japanese literature.

\section{The Current Situation and Problems of Modern Teaching Model}

\section{The Current Situation of Modern Teaching Model}

From the beginning of the eighties in the last century, the teaching model in China has undergone the following three stages: the first stage is the accumulation stage with introduction and practice; the second stage is mainly the stage of theoretical research and construction of subject teaching model; and the third stage is mainly the stage of practice construction and regional generalization. During the development of these three stages, from initially learning the experience from other people to innovating based on the country's own characteristics, the teaching model in China has been gradually developed. At present, more and more attention has been paid to the introduction of new theories of modern science and technology, and many teaching models begin to use the computer and network, achieving certain success[2]. As a result, the students can learn more and more knowledge, and their abilities to innovate become stronger and stronger.

\section{The Problems of Modern Teaching Model}

Utilitarianism--Teaching Model Has Gradually Become a Means of Becoming Famous for Some Schools Rather Than Means of Teaching

At present, due to the rapid development of information technology, teaching model has achieved an unprecedented flourish. However, in this prosperous stage, its drawbacks gradually emerge. Some schools use unconventional teaching models to win fame and honor[3]. Many schools exaggerate the advantages of the teaching model to attract students, so as to obtain a certain profit in enrollment fees. However, the issues regarding whether the teaching model can make students receive comprehensive development, and whether it is in line with the education philosophy of new 
curriculum reform are completely neglected by the schools which only value their reputation. These utilitarian pursuits often result in fickleness in the whole society and nation; scholars can not settle down to do research, and students can not get down to study hard, which makes the researchers lose their research abilities and some of the authentic specifications for academic research[4]. In the practice of education, it will also mistakenly enlarge the ability of teaching model; it is wrongly believed that the teaching model is able to solve any problems in teaching as long as it is good enough, and even the education departments of some regions carry out a certain teaching model which is said good, and require each school to employ the teaching model. The quality-oriented education is misunderstood by the society which only emphasizes on the teaching model instead of the students' own characteristics. Teaching model is not omnipotent. Different students have different characteristics; the good teaching model in your eyes may not be suitable for another student, then the student is unable to show his/her own characteristics, thus become the so-called "backward student".

Of course, the issue of utilitarianism is not a problem of an individual but a problem of the whole society. Since ancient times, prestige is extremely important in Chinese culture. The officials in ancient times must make some important contributions and achievements during their tenure, including the brilliant achievement in education; for example, the number of scholars in the region under their administration, etc. Then these achievements can be conductive to their promotion. At present, some schools are keen to apply for projects; it is even mandatory in some schools which do not care if students and teachers are willing or not. Although there are some positive factors in application of the project, the limiting factors such as teachers and students' time schedule make it difficult to achieve the expected project outcomes, and the utilitarianism in these issues cannot be ignored[5].

\section{Blindness--Lack of Innovation and Confusion in the Teaching Model and the Lack of Theoretical Support}

Many schools require teachers to innovate the teaching models and regard pursuing and summarizing new models as an approach for innovation. However, a lot of innovative teaching models, with different names, are not different in nature[6]. The teaching process is a process of interaction between teachers and students, and a process of exchange of ideas, which has its own characteristics.

At present, people blindly innovate teaching models, and always want to get rid of the stale and bring forth the fresh to create new models. However, teaching and learning are the most important in the teaching process, and teaching model is only a tool to achieve "teaching" and "learning". For "teaching", the teacher is an instructor who guide the students to appreciate the charm of knowledge and swim in the ocean of knowledge. "Learning" is student-centered, and students should follow the guidance of teachers to explore and learn, constantly enriching themselves. In the context of new curriculum reform and "people-oriented" viewpoint on students, the teachers believe that qualityoriented education refers to the student-centered class, and teachers are the servers of students. These teachers began to withdraw from the classroom; some teachers even give a lesson for a few minutes and left the rest time of class to students to discuss and learn by themselves. This is completely a misunderstanding of quality-oriented education. A classroom, the student is the subject of learning, and the teacher is the subject of teaching, not a single one can be omitted. Therefore, we should not blindly innovate the teaching model; we need to understand the characteristics of the students, and combine it with the characteristics of the lectures to innovate the teaching model, which is the best teaching model for both teachers and students[7].

\section{Casualness--the Presentation of Teaching Model Pays More Attention to the Novelty and is too Casual}

Different people have different views on the teaching model; the school principal and teachers have their own views, and students may have different ideas. We can not ask everyone to hold the same opinion, but the overall goal of teaching is identical, that is to let students learn knowledge, get growth and all-round development. In the process of teaching, teachers cannot always pursue the novel teaching model, as if they can win by using their own teaching model that nobody knows. 
In fact, no matter what kind of teaching model is used, the effectiveness is the most important. In the teaching process, if the teacher uses a novel teaching model, but the students cannot understand the contents of the lesson, then this novel teaching model is invalid and not feasible; on the contrary, if the traditional method of teaching can make students quickly understand what the teachers have taught, it is a good teaching model. A conscientious teacher should use different teaching models which are appropriate for different contents.

\section{Analysis of Network-Assisted Teaching Model and Traditional Routine Teaching Model}

\section{Advantages over the Traditional Teaching Model}

The traditional teaching system is composed of teachers, students and teaching materials. In the context of modern teaching, it is necessary to add an element - teaching media, then the teaching system consists of four parts, namely, teachers, students, teaching materials and teaching media. In a teaching system, we cannot simply piece several elements together, but need to make them interconnected and interact with each other to form an organic whole[8]. The advantages of network-assisted teaching over the traditional teaching model mainly include the following five aspects:

Firstly, the network-assisted teaching model is not limited by time and space, and the problems raised by the students can be solved in time. Due to the limited time in the classroom, students used to be unable to get timely solutions to the problems they encounter when doing homework after class, and now they can get a timely answer by asking the teacher through the network or searching the Internet. Secondly, the network-assisted teaching creates an interactive platform for teachers and students; at present, due to the frequently used APP of QQ and WeChat, teachers can communicate with students anytime and anywhere. Thirdly, the network-assisted teaching is useful for students to develop their self-study ability. In the past we learn the knowledge from the teachers, and now, because of the popularity of mobile phones, students can search the answers to the problems on the Internet, and browse the e-learning courseware[9], which greatly enhance the self-study ability of the students. Fourthly, due to the use of the network, the depth and breadth of the students' knowledge has been greatly improved. Through searching the answer to a problem on the Internet, we can learn all aspects of the related knowledge, which is useful for the knowledge reserve of students. Fifthly, the network-assisted teaching can help teachers improve the quality of teaching; using network-assisted teaching not only increases the knowledge of students but also improves the teaching ability of teachers. In the past, students usually simply smatter the complex contents in class, and now teachers can add music or video through the network in the process of teaching, so that students can have a deeper understanding on the knowledge.

\section{The Innovation of Network-Assisted Teaching}

The innovation of network-assisted teaching is to connect teachers, students and the outside world closely, rather than limiting them to the classroom. Students can achieve their purpose of learning through the network, and teachers can complete their teaching objectives through the network. The timeliness of the network enables students to find all the necessary contents in the shortest time. The richness of the web contents makes the students get more information in the process of searching and increase their knowledge reserve, laying a solid foundation for their future study.

\section{Study on the Strategy of Network-Assisted Japanese Literature Teaching}

\section{Course Background}

At present, there are many problems in the teaching of Japanese literature in our country, including the simple content of teaching materials, fewer teaching hours, single teaching methods and lower enthusiasm of students for learning Japanese literature. In order to solve these problems, the element - network will be added to the Japanese literature teaching to solve the relevant problems in the teaching of Japanese literature through the cooperation of teachers and the network. 


\section{Design of Network Course}

Topic of the course: Appreciation of Japanese literary works

Teaching hours: 32 hours

Teaching tool: Textbooks and web-videos

Teaching objectives: Ensure that the senior students of this major have a certain appreciation level towards the Japanese literary works

Focus and difficulty of teaching: Read and savor the studied literary works, deepen the impression through the video (such as anime and movies), and analyze the traits of the characters and the idea expressed by the author through appreciation.

Teaching media: Projection equipment and video equipment in the classroom

Teaching procedures:

Step 1: The teacher introduces the background and author of the literary works, and draws forth the content of the lesson.

Step 2: The teacher shows the courseware through PPT, and analyzes through combining the traits of characters and videos to arouse students' interest in learning and discussion.

Step 3: In the process of discussing the literary works with the students, the teacher slowly reveals the author's true intention and the thoughts expressed by the author through the analysis of traits of the characters.

Step 4: Fully develop the autonomy of students to make students participate in the class.

Step 5: The teacher summarizes the teaching effect of this lesson, and ask students to write a reading response or a review to express their own understanding on the studied literary works.

\section{Effect of the Design}

The above course design will give students a basic understanding of the Japanese literature. At the same time through the video students can have a preliminary understanding on each aspect of Japanese literature. The network-assisted teaching model solves the problem of single teaching method, and increases the interestingness of class and students' learning enthusiasm through the video and courseware[10].

\section{Reflection on Network-Assisted Teaching of Japanese Literature}

Through the network-assisted teaching, the teaching effect of Japanese literature can be greatly improved[11]. This not only enables the teacher to enrich their own knowledge in the process of preparing lessons, but also brings new changes in teaching due to the teaching model. In the process of teaching, students' enthusiasm for learning is increased, and teachers can interact with students, completing the teaching objectives. The purpose of learning Japanese literature is to widen the students' horizons, thereby increasing their knowledge. The traditional teaching model is that teachers speak, and the students listen, with single model and boringness. Network-assisted teaching involves the video and audio materials to enhance the students' subjective feelings, thus increasing the fun of learning. Therefore, at the moment, China should actively promote the network-assisted teaching model to enable students to enjoy the learning rather than passively receive knowledge.

\section{The Influence of Network-Assisted Teaching of Japanese Literature}

Network-assisted teaching have begun to be implemented in many schools, and its viability is obvious. With the assistance of the network, the boring knowledge of Japanese literature can be showed through the video, increasing the fun of learning. Moreover, in the process of teaching Japanese literature, students' interest in the network-assisted class is increased, and the students have a certain understanding on the network knowledge, which will influence the future teaching model, as well as learning model[12].

\section{Conclusion}

Information technology is rapidly developing, and the network has become the mainstream of teaching. For schools, the investment in network-assisted teaching needs to be increased to create an advanced scientific school. For teachers, learning network-assisted teaching model is the inevitable requirement of the moment; the network teaching model helps teachers to impart knowledge, and at 
the same time it enhances the teaching ability of teachers. As for students, they are in the stage of growth, and easy and dare to accept the new things, so they should study the scientific and cultural knowledge through the network to enrich their own knowledge reserve, to become the builders and supporters for the future of the country.

\section{References}

[1] He ZL. Research on the Application of Network Technology in Computer Aided Education [J]. Electronic Technology \& Software Engineering,2016,(03):34.

[2] Xie XF. A Study on the Teaching Strategies of British Literature in the Newly-built Universities in Western China [J]. Journal of Hubei Correspondence University, 2015,(08):150-151.

[3] Lian YP, Sun LC. A Study on Japanese Literature Teaching Assisted by Network Classroom [J]. China Adult Education,2015,(01):144-146.

[4]Cui JZ. The Cultivation of Students' Good Reading Habits in Technical Secondary School under the Network Teaching Environment [D].Hebei Normal University,2010.

[5]Wang WP. A Study on the Teaching Strategies of Foreign Literature in the Information Age [J]. The journal of Zaozhuang University,2009,(03):84-86.

[6]Wang JQ. Using Computer Assisted Instruction to Train Middle School Students' Autonomous Learning Ability [D]. Liaoning Normal University,2009.

[7]Shi JY. Research on Performance Test and Optimization Strategy of Distance Education System Based on WEB [D].Beijing University of Posts and Telecommunications, 2008.

[8]Man Y. The Teaching of Chinese Reading in Network Environment [D]. Qufu Normal University,2006.

[9]Peng Q. Design and Development of Multimedia - aided Japanese Teaching Courseware Based on Internet [D]. Northeast Normal University,2006.

[10]Mo XP. An Investigation on the Interaction of Network Teaching [D]. Shandong Normal University,2005.

[11]Feng QL. Discussion on Strategy of Vocabulary Development in Senior High School Students Based on Multimedia and Network Technology [D]. Central China Normal University,2003.

[12]Zeng QF. Research and Practice of the Application of Multimedia Technology in Biology Teaching [D]. Fujian Normal University,2002. 